University of South Carolina

Scholar Commons

Faculty Publications

Geography, Department of

1977

\title{
Network Characteristics in Suburbanizing Streams
}

William L. Graf

University of South Carolina - Columbia, grafw@mailbox.sc.edu

Follow this and additional works at: https://scholarcommons.sc.edu/geog_facpub

Part of the Geography Commons

\section{Publication Info}

Published in Water Resources Research, Volume 13, Issue 2, 1977, pages 459-463.

http://www.agu.org/journals/wr/

(c) 1977 by American Geophysical Union

This Article is brought to you by the Geography, Department of at Scholar Commons. It has been accepted for inclusion in Faculty Publications by an authorized administrator of Scholar Commons. For more information, please contact digres@mailbox.sc.edu. 


\title{
Network Characteristics in Suburbanizing Streams
}

\author{
WiLliam L. Graf \\ Department of Geography, University of Iowa, lowa City, lowa 52242
}

\begin{abstract}
Analysis of hydrologic, geomorphic, and suburbanization data from a small instrumented drainage basin near lowa City, lowa, indicates that channel networks are radically altered when suburban development overtakes a drainage basin. Changes in channel networks are such that the network becomes much more efficient in collecting water quickly, so that lag time and kurtosis of storm hydrographs are altered to produce the familiar fash floods of urban areas. The data show that network changes are closely associated with lag time and kurtosis of storm hydrographs and suggest that corrective measures should be concentrated on the internal links of the network. Changes in characteristics of channel networks should be considered in addition to changes in areas of impervious surfaces when the hydrologic impact of suburbanization is assessed.
\end{abstract}

\section{INTRODUCTION}

Dramatic responses in hydrologic and geomorphic systems occur when land use is converted from rural to suburban. The conversion of naturally vegetated surfaces that inhibit overland flow and promote infiltration to relatively impervious surfaces is well known [Leopold, 1968]. Roofs, sidewalks, streets, parking areas, and sod lawns accelerate overland flow and restrict infiltration, resulting in flood discharges of greater magnitude and frequency than those that occurred before suburbanization [Miller, 1972]. In turn, the geomorphic systems of channels and near-channel slopes respond to the hydrologic changes [Graf, 1976].

In addition to changes in surfaces, however, suburban development introduces another significant change into the hydrogeomorphic systems in the form of radical alteration of channel networks. Suburban development adds numerous artificial channels to the previously existing network of natural channels, so that the postdevelopment network is partly natural and partly artificial (Figure 1). The typical suburban channel network may have spatial characteristics that are substantially different from totally natural networks and that have profound effects on streamflow attributes. If the hydrologic responses to suburbanization are the product of overland flow and channel flow, analysis of surface alone provides only a partial explanation of the effects of development. The present report represents the results of an investigation into the changes in channel network characteristics that accompany suburbanization and demonstrates the effect of those changes on hydrologic systems.

Analysis of a small suburbanizing drainage basin and its associated stream network provides answers to the following questions: (1) How do stream networks change in suburbanizing areas? (2) How do network changes in suburbanizing areas affect the characteristics of stream discharge? The issues raised in regard to networks and discharge in suburban areas are significant from a variety of viewpoints. Answers to the above questions can provide useful input to the simulation models of hydrologists, aid the urban planner/designer in creating efficient suburban environments, and add a new perspective for the geomorphologist who must interpret natural analogs of the partly artificial suburban example.

\section{Data}

Data requirements for a hydrogeomorphic investigation into the relationships among suburbanization, channel net-

Copyright $\odot 1977$ by the American Geophysical Union. works, and hydrologic responses include the need for a relatively small drainage basin that has experienced substantial suburban development, that has a stream gage record spanning the significant period of suburbanization, and that has hourly precipitation data, as well as an extensive record of suburban developments in the form of frequent map and air photo coverage.

The South Branch of Ralston Creek, in Iowa City and Johnson County, Iowa, meets the data requirements. The basin covers a drainage area of approximately $7.7 \mathrm{~km}^{2}\left(3 \mathrm{mi}^{2}\right)$ and has relief of approximately $40 \mathrm{~m}(130 \mathrm{ft})$. The natural drainage network is developed on Kansan till, but soil development has been strongly affected by as much as $40 \mathrm{~cm}$ (16 in.) of Wisconsin age loess [Ruhe, 1969]. From the accounts of early settlers in the area the natural vegetation was dominated by hardwood forest with prairie openings, but by the late 1800 's most of the land was used for agricultural purposes. Annual rainfall in the area is about $81 \mathrm{~cm}$ (32 in.), with an average annual temperature of $10^{\circ} \mathrm{C}\left(50^{\circ} \mathrm{F}\right)$.

A stream gage has been in operation on South Branch since 1965 , and hourly precipitation data are available from a network of rain gages for all major storms since 1965. Gage and rainfall records along with a photographic record of land use changes are compiled into annual reports administered by the Institute of Hydraulic Research, University of Iowa.

There are numerous sources of data concerning the suburban development of South Branch. The earliest detailed map of the basin was published in 1839 (the year the city was founded), followed by numerous maps at average 15-year intervals until 1933. Aerial photography reveals the expansion of Iowa City into the South Branch basin for 10 dates between 1937 and 1975, supplemented by additional maps as well as field surveys made in 1975.

The maps, photos, and field evidence indicate that suburban development in South Branch has proceeded in a fashion very similar to the general model proposed by Hudson [1973], wherein development took place in a quilt work pattern, with some tracts of land intensely developed while nearby areas remain undeveloped. Land ownership, political boundaries, and transportation lines have exerted influences that resulted in sudden increases in intensity of basin development separated by periods when little or no development took place. A scale of several decades of observation, however, obscures the discontinuous nature of the suburban expansion (Figure 2).

\section{METHOD}

Accurate measurement of network changes requires varia- 

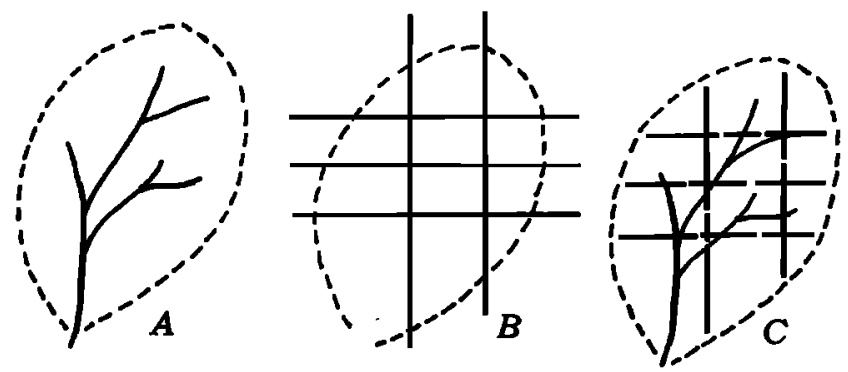

Fig. 1. Drainage network changes in a hypothetical suburbanizing network. ( $a$ ) The original natural network. (b) The street, gutter, and drain pattern superimposed on the natural pattern by suburbanization. (c) The total network, partly natural and partly artificial.

bles that specify the numerative, length, density, and other spatial characteristics of suburbanizing stream network. Changes in network variables then can be used as independent variables to explain observed changes in streamflow, especially storm runoff behavior. Although a large number of network variables might be used, significant amounts of autocorrelation and repetitive measurement exist among many network variables [Doornkamp and King, 1971]. Table 1 specifies and defines the limited number of network variables used in the present study, which uses the following basic topological definitions: (1) External links connect external nodes (points with single lines connecting them) with internal nodes (points with more than one line for connections). External links correspond to fingertip channels. (2) Internal links connect internal nodes.

A large number of variables are also available to provide measures of streamflow characteristics that depend in part on network characteristics. Lag time and kurtosis of storm hydrographs are of greatest interest in the suburban environment because they describe characteristics of streamflow that have significant impacts on land users in the near-channel environment.

Lag time $t_{l}$ is defined as the period in hours between the time of the center of mass of the given storm event and the time of the center of mass of the resulting storm hydrograph. Only discharges equal to or greater than $100 \mathrm{ft}^{3} / \mathrm{s}$ are considered in the present study. In suburban basins previously analyzed by other workers, lag time decreased as suburban land uses occupied increasing basin areas [Leopold, 1968].

In previous studies, kurtosis $K$, or peakedness of the storm hydrograph, also increased with increasing development, in- dicating the tendency of storm runoff in such areas to be 'flashier' than in similar undeveloped basins. In the present study, $K$ is defined as the moment coefficient of kurtosis:

$$
K=m_{4} / s^{4}
$$

where $m_{4}$ is the fourth moment about the mean and $s$ is the standard deviation [Spiegel, 1961]. For comparative purposes a normal or Gaussian distribution has $K=3.0$.

The relationship between suburbanization and network variables must be established before those variables are used in explanatory models with measures of streamflow characteristics. The degree to which suburbanization controls network variables can be assessed by comparing changes in the variables $V_{x}$ with various percentages of basin area suburbanized $A_{s}$. If suburbanization exerts strong influence on the network characteristics, significantly high correlation coefficients will obtain for the following relationship:

$$
V_{x}=a_{0}+b_{0} A_{s}
$$

The influence of network changes on storm hydrographs can be evaluated by using the following relationships:

$$
\begin{aligned}
& t_{1}=a_{1}\left(V_{x}\right)^{b_{1}} \\
& K=a_{2}\left(V_{x}\right)^{b_{2}}
\end{aligned}
$$

Power functions are the most appropriate function form based on previous research by numerous other workers [for example, Thomas and Benson, 1970]. Functions (3) and (4) can be solved by least squares methods if the variables are treated logarithmically:

$$
\begin{aligned}
& \log t_{l}=\log a_{1}+b_{1} \log V_{x} \\
& \log K=\log a_{2}+b_{2} \log V_{x}
\end{aligned}
$$

\section{RESULTS}

Analysis of the results shown in Tables 2, 3, and 4 demonstrates that suburbanization has a clear impact on stream network variables and that changes in those variables in turn influence streamflow.

The results in Table 2 show that characteristics of channel networks are very sensitive to the artificial links added during suburbanization. The total number of links increases as new streets and drains are added, so the relationship is clear between area of change and cumulative order, total length of interior links, and total length of exterior links. Because the

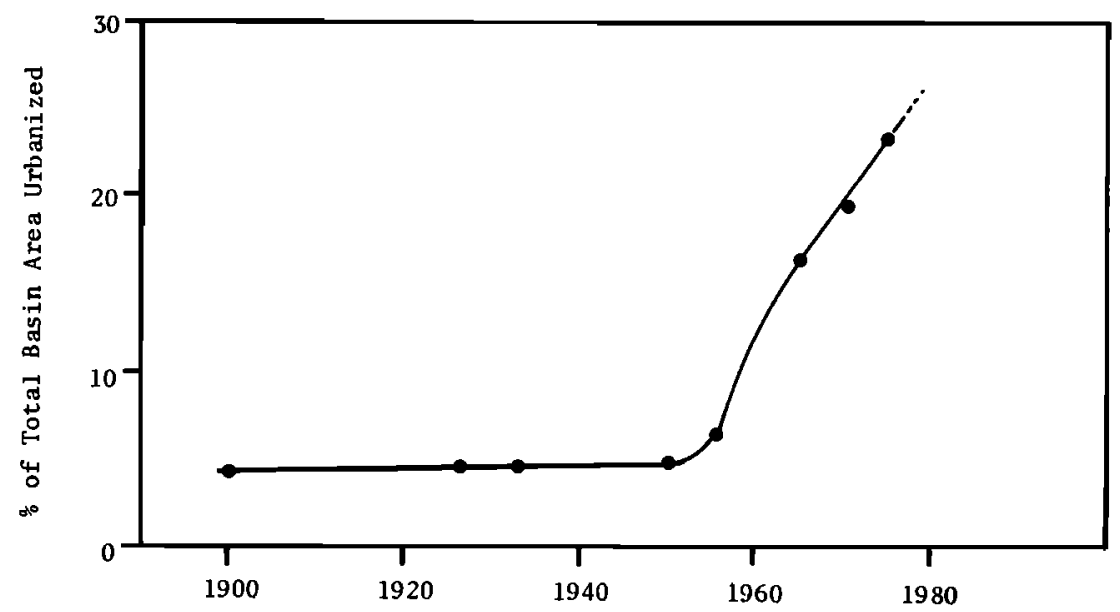

Fig. 2. Generalized suburbanization of South Branch. 


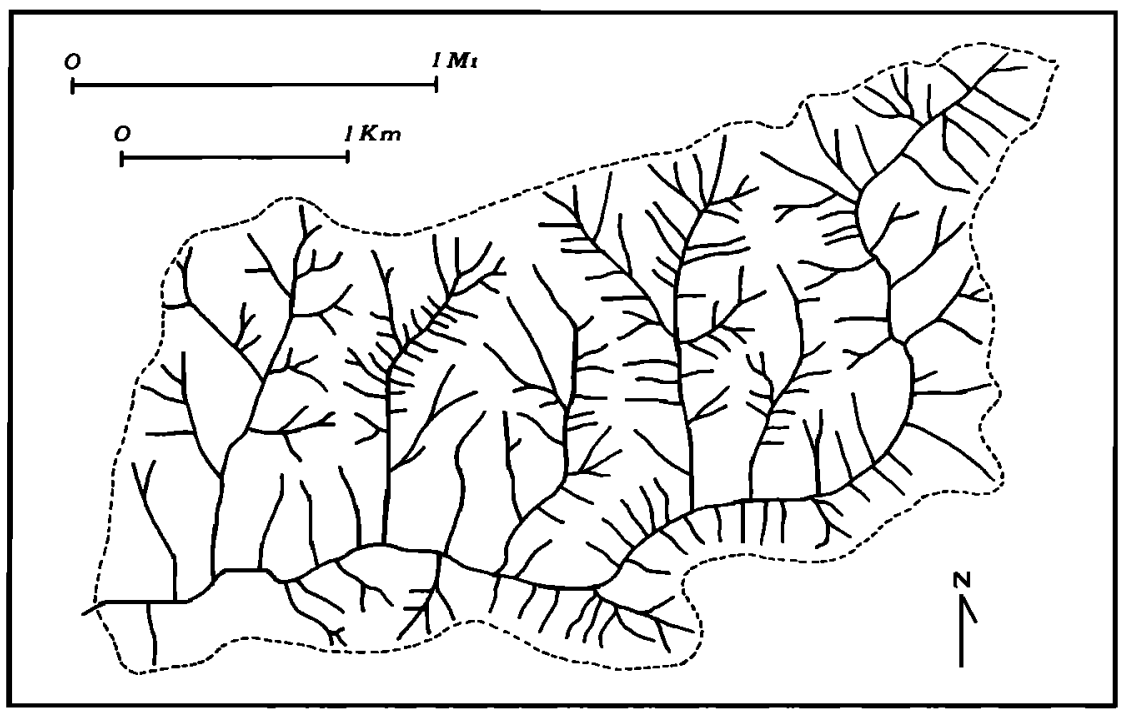

Fig. 3. The original natural channel network of South Branch.

drainage area remains unchanged during suburbanization, increases in the length of channels cause a commensurate change in drainage density. Data from networks mapped from historical maps and aerial photography show that the drainage density in 1975 in suburbanized South Branch was 50\% greater than that in the natural condition. The dramatic increase in drainage density has serious implications for hydrologic and geomorphic responses because a denser channel network insures rapid collection of runoff and reduced overland flow.

Although the mean length of internal and external links was not analyzed by means of regression, the mean length of external links decreased with the introduction of suburban channels, while the mean length of the internal links remained almost constant. These two trends suggest that the new channel network is more time efficient because flow from shortened external links is rapidly incorporated into the network.

Dimensionless variables that measure the relative importance of external versus internal drainage areas $\lambda$ and $a$, the shapes of subbasins $K_{e}$ and $K_{l}$, and the relative drainage densities $D_{e} / D_{t}$ are significantly related to the percent of subur- banized area because of the extensive changes in the network brought about by the addition of short exterior links and the segmentation of natural internal links. The introduction of triple junctions, uncommon in natural networks but common in artificial networks (at street junctions), contributes to changes in the dimensionless variables.

The relative linear and areal significance of external and internal link lengths and drainage areas is evaluated by $\lambda$ and $a$, respectively, with values of 1.0 indicating equality and values greater than 1.0 indicating greater significance of external links. Values of less than 1.0 indicate greater significance of internal links. Because long natural external links are divided into shorter internal links by the numerous small channels added by suburbanization, $\lambda$ and $a$ decrease with suburban development, a situation that accelerates runoff because of the rapid internalization of streamflow into the altered network.

The parameters $K_{e}$ and $K_{i}$ are shape parameters for external and internal drainage areas. Long narrow drainage areas produce values that are less than 1.0. If $K_{x}$ equals 1.0 , the drainage area is square or circular. Because street patterns tend to be

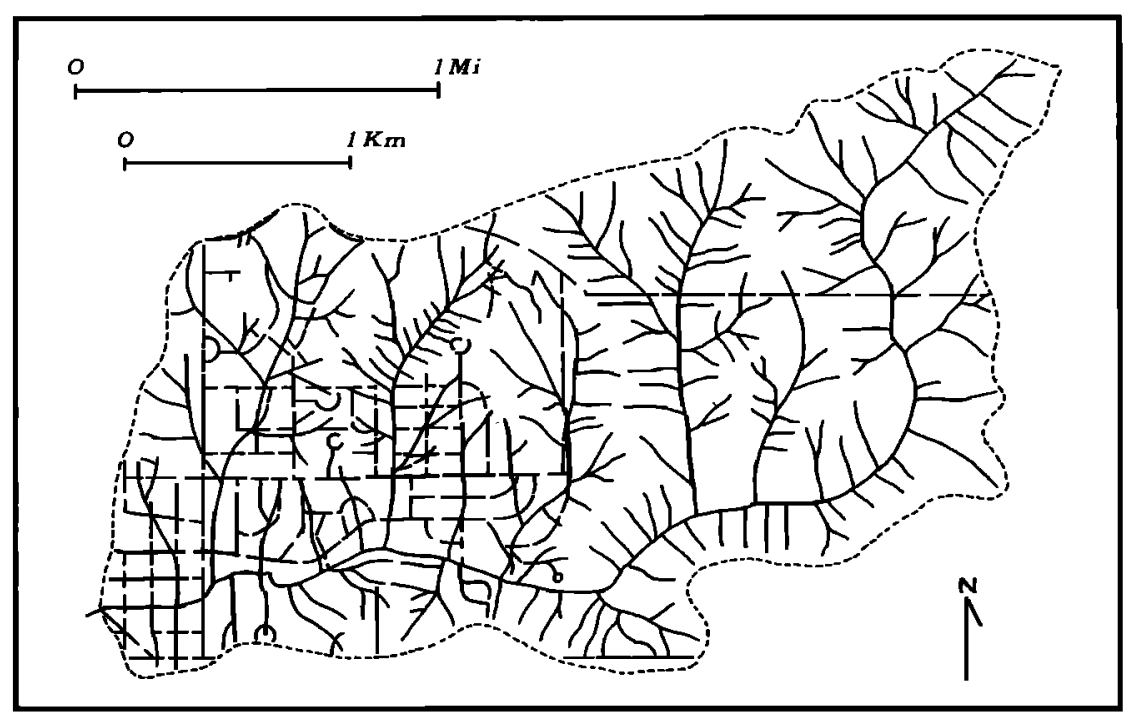

Fig. 4. The partly natural and partly artificial network of South Branch in 1975. 
TABLE 1. Variables Used in the Present Study

\begin{tabular}{|c|c|c|c|c|}
\hline Variable & Type & Units & Definition & Source \\
\hline$U_{\mathrm{c}}$ & Numerative & Number & $\begin{array}{l}\text { Total number of } \\
\text { links }\end{array}$ & Topology \\
\hline$l_{e}$ & Length & $L$ & $\begin{array}{l}\text { Total length of } \\
\text { exterior links }\end{array}$ & Topology \\
\hline$l_{l}$ & Length & $L$ & $\begin{array}{l}\text { Total length of } \\
\text { interior links }\end{array}$ & Topology \\
\hline$D$ & Density & $L^{-1}$ & $\begin{array}{c}L / A, \text { drainage } \\
\text { density }\end{array}$ & Horton [1945] \\
\hline$a$ & Dimensionless & & $\dot{a}_{e} / \tilde{a}_{i}$ & Smart [1972] \\
\hline$\lambda$ & Dimensionless & & $\Gamma_{e} / \Gamma_{i}$ & Smart [1972] \\
\hline$K_{e}$ & Dimensionless & & $\Gamma_{e}^{2} / \bar{a}_{e}$ & Smart [1972] \\
\hline$K_{l}$ & Dimensionless & & $\tilde{l}_{t}^{2} / \tilde{a}_{i}$ & Smart [1972] \\
\hline$D_{e} / D_{\ell}$ & Dimensionless & & $\lambda / a$ & Smart [1972] \\
\hline
\end{tabular}

rectangular, suburbanization of natural networks tends to produce $K_{x}$ values closer to unity than do natural networks. If the presuburban values are greater than 1.0, they are reduced; if they are less than 1.0 , they are increased. Values for $K_{\imath}$ demonstrate the expected trend; values for $K_{e}$ are inconclusive.

Although it is not apparent from the calculation equation (Table 1), $D_{e} / D_{\imath}$ represents a comparison between external and internal drainage densities: a value of 1.0 represents equal drainage densities, a value greater than 1.0 indicates that the external links have greater density, and a value less than 1.0 indicates that internal areas are more densely drained (see Smart [1972] for discussion). The introduction of large numbers of fingertip channels and the restricted partitioning of drainage areas by suburban development make an increase in values of $D_{e} / D_{t}$ a predictable companion of suburbanization.

Table 3 shows that the lag time of storm hydrographs is significantly responsive to changes in most of the network parameters. In each of the significant independent variables, changes with suburbanization tend to reduce length of overland flow and thus speed the accumulation process, resulting in reduced lag time. The reduction in length of internal links $l_{i}$, increasing significance of internal links $\lambda$, and the tendency toward rectangular shapes for internal drainage areas $K_{i}$ appear to be of special importance for reductions in lag time. Changes in external links that also accompany suburban development appear to be of little importance.

Table 4 shows that the kurtosis of storm hydrographs is also significantly responsive to most of the network variables but not the same set of variables as discussed above for lag time. The results in Table 3 indicate that kurtosis is strongly related to numerative and length measures (and their derivative measure of density), but the dimensionless variables seem to have little impact on the peakedness of the storm hydrograph. Apparently, the increased drainage density causes the discharge

TABLE 2. Solutions for the Equation $V_{x}=a_{0}+b_{0} A_{s}$

\begin{tabular}{lrccc}
\hline$V_{x}$ & \multicolumn{1}{c}{$a_{0}$} & \multicolumn{1}{c}{$b_{0}$} & \multicolumn{1}{c}{$r$} & Significance Level \\
\hline$U_{c}$ & 452.63 & 1754.39 & 0.984 & 0.01 \\
$l_{e}$ & 20.06 & 64.10 & 0.997 & 0.01 \\
$l_{l}$ & 14.50 & 32.15 & 0.999 & 0.01 \\
$D$ & 11.60 & 32.26 & 0.998 & 0.01 \\
$\lambda$ & 1.65 & -0.022 & 0.840 & 0.10 \\
$a$ & 1.82 & -3.49 & 0.943 & 0.02 \\
$K_{e}$ & 0.78 & 3.10 & 0.941 & 0.02 \\
$K_{l}$ & 0.65 & 0.019 & 0.827 & 0.10 \\
$D_{e} / D_{l}$ & 0.62 & 2.57 & 0.925 & 0.05 \\
\hline
\end{tabular}

to be collected rapidly and then to be disposed of rapidly, processes that are enhanced by numerous additions of artificial links to the natural network.

\section{Conclusions}

Data presented above suggest that there is a multiple answer to the question of how stream networks change in suburbanizing areas. In a suburbanizing network the number and cumulative lengths of links drastically increase in relationship to natural values, causing substantial increases in drainage density. Internal links become more significant than external links in terms of length and drainage area, while the shapes of subbasins become more rectangular. Additions of numerous external links insure that the density of external links is greater than the density of internal links.

Data presented above indicate that each of the network variables plays a role in answering the question of how network changes affect stream flow. Measures strongly related to characteristics of internal links are major vehicles for explaining lag time of the storm hydrograph, but numerative and length variables are most closely associated with hydrograph kurtosis. In each case, network variables change to reduce lag time and increase kurtosis.

The results reported above have three significant implications. First, assessors of the hydrologic impact of suburban developments who consider only changes in impervious surfaces risk ignoring an equally serious problem associated with drainage network changes. Second, the design and planning of suburban drainage networks must take into account the significant role of internal links in the network, where corrective measures designed to counter flood problems can have the greatest effect. Finally, geomorphologists concerned with variation in natural networks can find useful analogs in the partly natural and partly artificial suburban environment.

TABLE 3. Solutions for the Equation $t_{1}=a_{1}\left(V_{x}\right)^{b_{1}}$

\begin{tabular}{lrrrc}
\hline \multicolumn{1}{c}{$V_{x}$} & \multicolumn{1}{c}{$a_{1}$} & \multicolumn{1}{c}{$b_{1}$} & \multicolumn{1}{c}{$r$} & Significance Level* $^{c}$ \\
\hline$U_{c}$ & 1475.50 & -0.93 & -0.95 & 0.02 \\
$l_{e}$ & 41.84 & -0.42 & -0.75 & NS \\
$l_{r}$ & 31.59 & -0.63 & -0.96 & 0.01 \\
$D$ & 24.50 & -0.50 & -0.86 & 0.10 \\
$\lambda$ & 0.82 & 0.57 & 0.98 & 0.01 \\
$a$ & 0.75 & 0.65 & 0.82 & 0.10 \\
$K_{e}$ & 1.18 & 0.14 & 0.24 & NS \\
$K_{t}$ & 2.12 & -1.04 & 0.97 & 0.01 \\
$D_{e} / D_{t}$ & 1.11 & -0.08 & -0.16 & NS \\
\hline
\end{tabular}

* NS means not significant. 
TABLE 4. Solutions for the Equation $K=a_{2}\left(V_{x}\right)^{b_{8}}$

\begin{tabular}{lrrrc}
\hline$V_{x}$ & $a_{2}$ & \multicolumn{1}{c}{$b_{2}$} & \multicolumn{1}{c}{$r$} & Significance Level \\
\hline$U_{c}$ & 92.94 & 1.43 & 0.99 & 0.01 \\
$l_{e}$ & 5.35 & 1.20 & 0.96 & 0.01 \\
$l_{l}$ & 5.04 & 0.94 & 0.98 & 0.01 \\
$D$ & 3.43 & 1.10 & 0.97 & 0.01 \\
$\lambda$ & 1.64 & -0.19 & -0.64 & $\mathrm{NS}$ \\
$a$ & 7.52 & -1.26 & -0.80 & $\mathrm{NS}$ \\
$K_{e}$ & 0.26 & 1.11 & 0.87 & 0.10 \\
$K_{t}$ & 0.77 & 0.18 & 0.63 & $\mathrm{NS}$ \\
$D_{e} / D_{t}$ & 0.21 & 1.10 & $\mathbf{0 . 8 5}$ & 0.10 \\
\hline
\end{tabular}

* NS means not significant.

\section{REFERENCES}

Doornkamp, J. C., and C. A. M. King, Numerical Analysis in Geomorphology, St. Martin's Press, New York, 1971.

Graf, W. L., Streams, slopes, and suburban development, Geogr. Anal., 8, 153-173, 1976.
Horton, R. E., Erosional development of streams and their drainage basins: Hydro-physical approach to quantitative morphology, Geol. Soc. Amer. Bull., 56, 275-370, 1945.

Hudson, J., Density and pattern in suburban fringes, Ann. Ass. Amer. Geogr., 63, 28-39, 1973.

Leopold, L. B., Hydrology for urban land planning-A guidebook on the hydrological effects of urban land use, U.S. Geol. Surv. Circ., 554, 1968.

Miller, C. R., Runoff volumes from small urban watersheds, Water Resour. Res. 8, 429-434, 1972.

Ruhe, R. V., Quarternary Landscapes in Iowa, Iowa State University Press, Ames, lowa, 1969.

Smart, J. S., Quantitative characterization of channel network structure, Water Resour. Res., 8, 1487-1496, 1972.

Spiegel, M. S., Theory and Problems of Statistics, McGraw-Hill, New York, 1961.

Thomas, D. M., and M. A. Benson, Generalization of streamflow characteristics from drainage basin characteristics, U.S. Geol. Surv. Water Supply Pap., 1975, 1970.

(Received June 1, 1976; accepted December 23, 1976.) 